\title{
Molecular detection evaluation of pneumonia- associated fastidious pathogens and comparison to conventional microbiological results
}

\author{
Matthias Karrasch, J ürgen Rödel, Peter M. Keller, Astrid Sobke, Wolfgang Pfister, Eberhard \\ Straube
}

Institute of Medical Microbiology, University Hospital of Friedrich Schiller University, Jena, Germany

Correspondence: Matthias Karrasch. Address: Institute of Medical Microbiology University Hospital of Friedrich-SchillerUniversity, Jena, Germany. E-mail: matthias.karrasch@med.uni-jena.de

Received: November 19, 2014

Accepted: December 29, 2014 Online Published: January 21, 2015

DOI : $10.5430 /$ crcp.v2n2p66

URL: http://dx.doi.org/10.5430/crcp.v2n2p66

\section{Abstract}

Introduction: Microbiological diagnosis for pneumonia causing pathogens refractory to cultivation is frequently slow for clinical decision taking. Fastidious pathogen identification using new molecular techniques might accelerate appropriate antibiotic treatment start in patients.

Objectives: We investigated a prototype multiplexed pneumonia test covering the three pneumonia-causing fastidious pathogens Legionella pneumophila, Chlamydia pneumoniae, Moraxella catarrhalis and 22 resistance genes.

Methods: Results were obtained in 302 hospitalized patients with suspected pneumonia by examining BAL, tracheal secretion and sputum material. Molecular test results were compared to conventional culture, biochemical test, serology and antimicrobial susceptibility testing (AST) results as validated methods. Discrepant results were evaluated in context of patient treatment and outcome in order to assess impact and relevance of molecular results.

Results: Among 302 patients, potentially relevant fastidious pathogens were detected in only 4 patients by molecular analysis: L. pneumophila $(\mathrm{n}=3)$, C. pneumoniae $(\mathrm{n}=1)$, M. catarrhalis $(\mathrm{n}=1)$. Of these, only the signal for $M$. catarrhalis was above the threshold proposed by the manufacturer. The device detected possibly associated resistance markers: ermB (L. pneumopila, C. pneumoniae), ermC (L. pneumophila) and mefA (M. catarrhalis). These resistance markers were not associated to the pathogens identified by the molecular technique. In contrast, the conventional culture technique identified Enterococcus faecium $(\mathrm{n}=1)$, Enterobacter aerogenes $(\mathrm{n}=2)$ and Acinetobacter baumannii $(\mathrm{n}=1)$ with relevant resistances: gentamicin high-level (E. faecium), piperacillin/tazobactam and ceftazidim (E. aerogenes), and ampicillin/sulbactam and ciprofloxacin (A. baumannii).

Conclusion: Of the cases in which fastidious bacterial DNA could be detected, only one case ( $M$. catarrhalis) was relevant according to system threshold, but clinical relevance remained unclear. Erythromycin-resistance was indicated by the system without corresponding pathogen identification. It appears that detected resistance genes were associated with respiratory flora, thereby possibly misleading the clinician. On the other hand, nosocomial pathogens detected by conventional techniques were not sufficiently covered by the system. Taken together it seems that system specificity for fastidious pneumonia pathogens might be sufficient but results for resistance genes did not correspond to results of pathogen identification. 


\section{Key words}

Fastidious pathogens, Pneumonia, Molecular diagnostics

\section{I ntroduction}

Delay in microbiology culture diagnostics for pneumonia-causing pathogens refractory to cultivation is a clinical problem which often results in empirical, sometimes inefficient, broad-spectrum antibiotic therapy until final microbiology results become available. Identification by molecular techniques might accelerate appropriate treatment of both ventilatorassociated pneumonia (VAP) and community-acquired pneumonia (CAP) ${ }^{[1,2]}$ which is of special importance for patients treated in intensive care untis (ICU) ${ }^{[3]}$. We investigated the Unyvero ${ }^{\mathrm{TM}}$ prototype with cartridge P50 covering 17 pneumonia-causing pathogens, among them the fastidious pneumonia-causing pathogens Legionella pneumophila ${ }^{[4]}$ and Chlamydia pneumoniae ${ }^{[5,6]}$, which are clinically important in immunocompromised patients ${ }^{[4,7]}$. Moraxella catarrhalis ${ }^{[8]}$ is a pathogen which can be overlooked easily as it looks similar to other commensal bacteria of the normal flora ${ }^{[9]}$. Bacterial resistance to many antibiotic treatment options is a growing clinical problem throughout the world. Antimicrobial susceptibility testing (AST) using either microdiluting methods or automated techniques is the current gold-standard for pathogen resistance detection ${ }^{[10]}$. Molecular methods for detecting antibiotic resistance are on the rise $^{[11,12]}$, but these methods still need to be compared to AST results ${ }^{[13-15]}$.

\section{Material and methods}

Results were obtained in 302 hospitalized patients with suspected pneumonia by examining broncho-alveolar lavage (BAL), tracheal secretion and sputum material using the Unyvero ${ }^{\mathrm{TM}}$ pneumonia prototype (Curetis AG, Holzgerlingen, Germany). This study intended to compare the established standard-of-care for pathogen and antibiotic resistance detection to the Unyvero ${ }^{\mathrm{TM}}$ prototype pneumonia application. It also intended to aid in the diagnosis of pneumonia by identifying genes of 17 pathogens, including fastidious pathogens (Acinetobacter baumannii, Enterobacter spp., Escherichia coli, Chlamydia pneumonia, Haemophilus influenzae, Moraxella catharalis, Streptococcus pneumoniae, Haemophilus influenza, Legionella pneumophilia, Klebsiella pneumoniae, Klebsiella oxytoca, Morganella morganii, Pneumocystis jirovecii, Proteus spp., Pseudomonas aeruginosa, Serratia marcescens, Staphylococcus aureus, Stenotrophomonas maltophilia), and in the detection of 22 resistance gene markers (tem, shv, ctx-M, dha, ebc, kpc, oxa51, mecA, msrA, ermB, mefA/E, int1, sul1, gyrA83, gyrA87, parC) associated with antibiotic resistance ${ }^{[16]}$. Test results were compared to findings of conventional culture and AST. A control of the results by another molecular technique like 16S rRNA gene PCR was not possible, as samples from the respiratory tract are usually contaminated by several microorganisms. This leads to mixed sequences in the amplicon averting a sufficient sequencing of nucleotides. Discrepant results were evaluated in context of patient treatment and outcome to assess impact and relevance of molecular results.

\section{Results}

Fastidious pathogens were detected in only four patients out of 302 patients enrolled at our site. In these patients, detection signal differences were seen between the Unyvero ${ }^{\mathrm{TM}}$ prototype and conventional microbiology for fastidious pneumonia causing pathogens. Unyvero ${ }^{\mathrm{TM}}$ prototype detected the fastidious pathogens Legionella pneumophila $(\mathrm{n}=3)$, Moraxella catarrhalis $(\mathrm{n}=1)$, and Chlamydia pneumoniae $(\mathrm{n}=1)$ in four different patients which have not been detected by conventional microbiology. In two of these patients, Stenotrophomonas maltophila $(\mathrm{n}=2)$ as a non-fastidious pathogen was detected only by the Unyvero ${ }^{\mathrm{TM}}$ prototype. Of these, only the signal for $M$. catarrhalis was above the threshold proposed by the manufacturer. In these four patients, Unyvero ${ }^{\mathrm{TM}}$ prototype application system was in addition able to detect different possibly associated resistance genes ermB (L. pneumopila, C. pneumoniae), ermC (L. pneumophila) and mefA (M. catarrhalis) (see the table). Parallel conventional diagnostic grew Enterococcus faecium $(\mathrm{n}=1)$, Enterobacter 
aerogenes $(\mathrm{n}=2)$ and Acinetobacter baumannii $(\mathrm{n}=1)$ with relevant resistances: gentamicin high-level $(E$. faecium), piperacillin/tazobactam and ceftazidim (E. aerogenes), and ampicillin/sulbactame and ciprofloxacin (A. baumannii). The patient with $M$. catarrhalis suffered from infection-exacerbated COPD, conventional culture showed low colony-forming unit (CFU) numbers of E. aerogenes. Treatment with meropenem was successful, making this case ambiguous. For two other pathogens (Streptococcus pneumoniae, Stenotrophomonas maltophilia) the detection signals seemed to be false positive in our small sub-analysis (see the table).

Table. Comparison of Unyvero ${ }^{\mathrm{TM}}$ prototype results with conventional microbiology results for pathogens recalcitrent to cultivation

\begin{tabular}{|c|c|c|c|c|}
\hline & \multicolumn{2}{|c|}{ Unyvero $^{\mathrm{TM}}$ Application System } & \multicolumn{2}{|c|}{ Conventional Microbiology } \\
\hline & Germs & Resistance Genes & Germs & Antibiogram Resistance \\
\hline Patient 1 & $\begin{array}{l}\text { Legionella pneumophilia } \\
\text { Stenotrophomonas maltophilia }\end{array}$ & ermB \& erm $C$ & $\begin{array}{l}\text { Enterococccus faecium } \\
\text { Candida famata }\end{array}$ & $\begin{array}{l}\text { gentamicin high-level }{ }^{*} \\
\text { quinolones }\end{array}$ \\
\hline Patient 2 & $\begin{array}{l}\text { Legionella pneumophilia } \\
\text { Stenotrophomonas maltophilia }\end{array}$ & ermB & $\begin{array}{l}\text { Enterobacter aerogenes* } \\
\text { Yeasts }\end{array}$ & $\begin{array}{l}\text { ampicillin*, } \\
\text { ampicillin/sulbactam } \\
\text { cefuroxime }\end{array}$ \\
\hline Patient 3 & $\begin{array}{l}\text { Legionella pneumophilia } \\
\text { Moraxella catharralis } \\
\text { Streptococcus spp. }\end{array}$ & $\begin{array}{l}\text { ebc } \\
\text { ermB \& erm } C \\
\text { mefA }\end{array}$ & $\begin{array}{l}\text { Enterobacter aerogenes* } \\
\text { Streptococcus spp. }\end{array}$ & $\begin{array}{l}\text { ampicillin*, } \\
\text { ampicillin/sulbactam* } \\
\text { piperacillin/tazobactam* } \\
\text { cefuroxime }{ }^{*} \text { cefotaxime* } \\
\text { ceftazidime* }\end{array}$ \\
\hline Patient 4 & $\begin{array}{l}\text { Chlamydia pneumoniae } \\
\text { Proteus spp. }\end{array}$ & ermB & $\begin{array}{l}\text { Coagulase-negative } \\
\text { staphylococci, } \\
\text { Proteus mirabilis } \\
\text { Acinetobacter baumannii } \\
\text { Candida glabrata }\end{array}$ & $\begin{array}{l}\text { ampicillin", } \\
\text { ampicillin/sulbactam*, } \\
\text { cefuroxime*, } \\
\text { cefotaxime*, } \\
\text { ciprofloxacin }\end{array}$ \\
\hline
\end{tabular}

Note. *Relevant AST results for conventional pathogen finding

Three of these patients passed away during study period, one patient survived. Antibiotic treatment was either done empirically or based on conventional antibiogram. Unyvero ${ }^{\mathrm{TM}}$ prototype results were not sent to the clinical site as application is not validated yet clinically. The initial antibiotic treatment against radiologically confirmed pneumonia of case 1 (68 year old Caucasian) consisted of sultamicillin and roxithromycin, but was not sufficient as patient was re-admitted to hospital with similar clinical signs of dyspnoea. At this time, pulmonary embolism was diagnosed. Lysis therapy plus interventional thrombectomy was started immediately. The initial antibiotic treatment was re-started without any improvement in respiratory function. Liver transaminases and coagulation parameters deteriorated and acute liver failure was suggested. The patient had a travel history to China some weeks before his hospitalisation. Hepatitis serology was positive for hepatitis E IgG antibodies. Conventional BAL analysis showed Enterococcus faecium (sensitive to vancomycin and linezolid), also detected in central venous blood culture, and Candida famata (sensitive to fluconazole, voriconazole, amphotericin B and itraconazole). The E. faecium isolate showed high-level resistance to gentamicin in AST. Legionella pneumophila IgG and IgM ELISA were negative. Viral analysis was negative for CMV pp65, EBV quantitative PCR, VZV PCR, HHV-6 PCR, HIV quantitative PCR and Adenovirus qualitative PCR. ELISA serology (IgG/IgM/IgA) was negative for herpes simplex virus, cytomegalovirus, Epstein-Barr-virus, varizella zoster virus, influenza A, influenza B and parainfluenza 1, 2 and 3. ECG and cranial CT was normal. Abdominal sonography showed slight hepatomegaly with normal blood flow. Chest X-Ray revealed shadows in left upper field and right lower field of lung with mediastinal fluid left. Calculated initial meropenem therapy was chosen from the treating physician for the treatment of Enterococcus bacteremia until AST results became available. Patient developed rising body temperatures, progredient infiltrates in lung, rising CRP levels, leucocytosis, anemia and thrombocytopenia. Patient developed sepsis and died in multiorgan failure a few days later. Unyvero ${ }^{\mathrm{TM}}$ prototype was able to detect additionally two germs (Legionella pneumophilia and Stenotrophomonas maltophilia) in this patient. In the Unyvero ${ }^{\mathrm{TM}}$ resistance gene analysis, macrolide resistance genes ermB and ermC were detected as well. 
Case 2 was a 68 year old woman who was admitted with acute left sided subarachnoidal and intracranial bleeding due to a rupture of a left arteria cerebri media aneurysma. Unyvero ${ }^{\mathrm{TM}}$ prototype results showed Stenotrophomonas maltophilia and Legionella pneumophila value around the pre-defined threshold which have not been detected by conventional microbiology. ermB resistance gene was detected. Initial calculated treatment consisted of trimethoprim and sulfamethoxazole (co-trimoxazole). Despite hemicranectomy and clip support of aneurysma rupture patient passed away within one month. Clinical signs of pneumonia (cough, dyspnoea, fever) were evident, although no infiltrates were seen in chest X-Ray.

Case 3 is on the waiting list for lung transplantation due to stage IV COPD and lung emphysema. Patient was admitted to hospital with worsening shortness of breath. Bronchoscopy showed acute bronchitis and BAL was undertaken. Conventional microbiology results showed Enterobacter aerogenes in BAL. Enterococcus faecium and coagulase-negative staphylococci were found at the catheter tip, an antibiogram-adapted treatment against Enterococcus faecium was started. ELISA showed $10.00 \mathrm{mg} / \mathrm{L}$ antibodies against pneumococcal capsule polysaccharide. No Pneumocystis jirovecii was found microscopically. HSV, CMV, VZV and Influenza A/B PCR were negative. Aspergillus antigen as well as Cryptococcus antigen were not detected serologically. As no infiltrates were seen in the chest X-Ray, diagnosis of pneumonia was defined clinically. Patient was treated with clarithromycin, linezolid and meropenem. Streptococcus pneumoniae and Moraxella catarrhalis and ebc, ermC, mefA, ermB resistance genes were detected by Unyvero $^{\mathrm{TM}}$ Application System in BAL samples from this patient. In addition, an amplification signal for Legionella pneumophila below the threshold was detected by the Unyvero ${ }^{\mathrm{TM}}$ Application System. Patient survived this episode and is still on waiting list for lung transplantation.

Case 4 was admitted to the hospital with acute left-sided chest pain, elevated troponine I laboratory values and ST-segment depression in ECG. 3-vessel coronary heart disease was confirmed following heart catheter examination, thus heart surgery was performed. Patient was reintubated after heart surgery due to food aspiration and respiratory problems. The patient developed rising infection signs and elevated CRP level. An empiric antibiotic treatment with meropenem and vancomycin was started due to the development of infiltrates in chest X-Ray. Proteus spp. and C. pneumophila below system threshold and ermB-resistance gene were detected by Unyvero ${ }^{\mathrm{TM}}$ prototype in BAL samples from this patient. The patient did not receive any immunosuppressive therapy. Conventional microbiology results showed coagulase-negative Staphylococci, Proteus mirabilis, Acinetobacter baumannii and Candida glabrata in BAL, as well as Candida glabrata in one blood culture at different time points. Patient underwent gastroscopy due to gastric bleeding, and was treated with adrenaline injection at antrum bleeding site. Despite antibiotic and gastroscopic treatment patient's condition worsened and patient passed away in septic shock. An obduction was done in which death due to bacterial sepsis and multiple organ failure was confirmed.

\section{Discussion}

As a monocentric experience, Unyvero ${ }^{\mathrm{TM}}$ prototype system used in our study was able to detect fastidious germs in 4 out of 302 patients (L. pneumophila [n = 3], C. pneumoniae [n=1], M. catarrhalis [n=1]). Of these, only the signal for $M$. catarrhalis was above the threshold proposed by the manufacturer. In addition, in these 4 cases the device detected possibly associated resistance markers: ermB (L. pneumopila, C. pneumoniae), ermC (L. pneumophila) and mefA (M. catarrhalis). Conventional diagnostic grew Enterococcus faecium $(\mathrm{n}=1)$, Enterobacter aerogenes $(\mathrm{n}=2)$ and Acinetobacter baumannii $(\mathrm{n}=1)$ with relevant resistances: gentamicin high-level $(E$. faecium), piperacillin/tazobactam and ceftazidime (E. aerogenes), and ampicillin/sulbactam and ciprofloxacin (A. baumannii). The patient with $M$. catarrhalis suffered from infection-exacerbated COPD, conventional culture showed low number of E. aerogenes. Treatment

with meropenem was successful, making this case ambiguous. In case 1, secondary pulmonary hypertension from CT-confirmed pulmonary embolism and hepatitis E virus-caused acute liver failure might have been worsened by enterococcus-caused sepsis (detected by conventional microbiology), resulting in multi-organ failure. It is of doubt that 
these clinical symptoms were even more worsened by Legionella pneumophilia or Stenotrophomonas maltophilia, detected by Unyvero ${ }^{\mathrm{TM}}$ prototype system, not detected by conventional microbiology (Legionella IgG / IgM ELISA negative]. Unyvero ${ }^{\mathrm{TM}}$ prototype system detected macrolide resistance genes erm $C$ and ermB (coding for a macrolide-inactivating enzymes) were not of clinical significance as Enterococcus spp. was treated with roxithromycin. The resulting conventional antibiogram was appropriate and lead to antibiogram-adapted immediate therapy against conventionally detected Enterococcus faecium, which was not detected by Unyvero ${ }^{\mathrm{TM}}$ prototype application system, as this germ is not in the panel of this application. Legionella-specific radiological findings were not evident, but initial roxithromycin therapy should have been useful in the treatment of this potential Legionella infection as well. Legionella signal was below Unyvero ${ }^{\mathrm{TM}}$-threshold, thus it can be speculated that only non-viable Legionella-DNA was detected without any clinical significance, maybe even caused by contamination. In case 2, patient deceased from massive cerebral bleeding. There is no evidence that a change of antibiotic treatment following the Unyvero ${ }^{\mathrm{TM}}$ results would have changed this fatal outcome. In case 3, detection of antibodies against pneumococcal capsule polysaccharide as a clinical marker for vaccination against $S$. pneumoniae was detected by Unyvero ${ }^{\mathrm{TM}}$ system, which could be suggestive for an acute pneumococcus infection with a different serotype. Thus, Unyvero ${ }^{\mathrm{TM}}$ application system might have been the better diagnostic procedure for the detection of this germ. As in case 1, it is not clear if low grade Legionella detection was not caused by contamination, as no pneumonia-specific radiological findings were detected and initial treatment included antibiotic treatment against Legionella. The detected resistance genes might well be coding for macrolide-resistance in pneumococci, but this finding was not relevant under the antibiotic treatment received. Unyvero ${ }^{\mathrm{TM}}$-detected Moraxella catarrhalis might have well been responsible for respiratory problems, but this germ was well covered with the antibiotic treatment provided. In case 4 , it is questionable if the Unyvero ${ }^{\mathrm{TM}}$-detected Chlamydia result was of any clinical significance, as pathogen detection was below the Unyvero ${ }^{\mathrm{TM}}$ Chlamydia threshold and sepsis was confirmed by autopsy. Moreover, a potential pneumonia caused by anaerobic germs or by the relative frequent CAP-causing fastidious pathogen Mycoplasma pneumonia ${ }^{[17]}$ was not detected by the molecular prototype device, as these pathogens were not included in the panel.

\section{Conclusions}

Of the four cases in which fastidious bacterial DNA could be detected, only one case ( $M$. catarrhalis) was relevant according to system threshold, but clinical relevance remained unclear. Although Unyvero ${ }^{\mathrm{TM}}$ prototype was able to detect pathogens recalcitrant to cultivation, it is questionable if this was of clinical significance in the cases reported as the viability of the organism that harbored the detected DNA remained unclear. In all four cases, erythromycin-resistance was indicated by the system without corresponding pathogen identification. It appears that detected resistances were associated with respiratory flora, thereby possibly misleading the clinician. On the other hand, nosocomial pathogens detected by conventional techniques were not sufficiently covered by the system. Taken together, it seems that the prototype system specificity for fastidious pneumonial pathogens has to be optimized and results of resistance gene detection should be taken with care. It also remains unclear if detections would have led to a different clinical outcome in the cases reported. The frequently CAP-causing fastidious pathogen Mycoplasma pneumoniae should also be included in an updated panel. Further analysis in a future study with an optimized molecular diagnosis system is therefore urgently needed for fastidious pathogens.

\section{Acknowledgement}

The authors would like to thank Sylvia Stoll, Christine Bär and Angelika Saupe for their dedicated technical working skills within this clinical study.

Preliminary study results were demonstrated as poster presentation during the American Society of Microbiology (ASM) General Meeting 2014 in Boston, Massachusetts. 


\section{References}

[1] Bogaerts P, Hamels S, de Mendonca R, Huang TD, Roisin S, Remacle J, et al. Analytical validation of a novel high multiplexing real-time PCR array for the identification of key pathogens causative of bacterial ventilator-associated pneumonia and their associated resistance genes. J Antimicrob Chemother. 2012 Oct 12. [Epub ahead of print]

[2] Wang L, Gu H, Lu X. A rapid low-cost real-time PCR for the detection of Klebsiella pneumonia carbapenemase genes. Ann Clin Microbiol Antimicrob. 2012 Jun 18; 11: 9. PMid: 22545713. http://dx.doi.org/10.1186/1476-0711-11-9

[3] Dwivedi M, Mishra A, Azim A, Singh RK, Baronia AK, Prasad KN, et al. Ventilator-associated pneumonia caused by carbapenem-resistant Enterobacteriaceae carrying multiple metallo-beta-lactamase genes. Indian J Pathol Microbiol. 2009 Jul-Sep; 52(3):339-42. PMid: 19679955. http://dx.doi.org/10.4103/0377-4929.54988

[4] Friedman H, Yamamoto Y, Klein TW. Legionella pneumophila pathogenesis and immunity. Semin Pediatr Infect Dis. 2002 Oct; 13(4): 273-9. PMid: 12491233. http://dx.doi.org/10.1053/spid.2002.127206

[5] Lamoth F, Greub G. Fastidious intracellular bacteria as causal agents of community-acquired pneumonia. Expert Rev Anti Infect Ther. 2010 Jul; 8(7): 775-90. PMid: 20586563. http://dx.doi.org/10.1586/eri.10.52

[6] Cunha BA. The atypical pneumonias: clinical diagnosis and importance. Clin Microbiol Infect. 2006 May; 12 Suppl 3: 12-24. PMid: 16669925. http://dx.doi.org/10.1111/j.1469-0691.2006.01393.x

[7] M. T. Kauppinen, P. Saikku, P. Kujala, E. Herva, H. Syrjälä. Clinical picture of community-acquired Chlamydia pneumoniae pneumonia requiring hospital treatment: a comparison between chlamydial and pneumococcal pneumonia. Thorax. 1996 February; 51(2): 185-189. PMid: 8711653. http://dx.doi.org/10.1136/thx.51.2.185

[8] Johnson MA, Drew WL, Roberts M. Branhamella (Neisseria) catarrhalis--a lower respiratory tract pathogen? J Clin Microbiol. 1981 Jun; 13(6): 1066-9. PMid: 7251828.

[9] Goldstein Ellie J.C., Murphy Timothy F., Parameswaran G. Iyer. Moraxella catarrhalis, a Human Respiratory Tract Pathogen. Clin Infect Dis. 2009; 49 (1): 124-131. PMid: 19480579. http://dx.doi.org/10.1086/599375

[10] Reller, L.B., Weinstein M., Jorgensen, J.J., Ferrano, M.J. Antimicrobial Susceptibility Testing: A Review of General Principles and Contemporary Practices. Clin Infect Dis. 2009; 49 (11): 1749-1755. PMid: 19857164. http://dx.doi.org/10.1086/647952

[11] Kakinuma Y, Maeda Y, Mason C, Goldsmith CE, Coulter WA, Matsuda M, et al. Moore JE. Molecular characterisation of the quinolone resistance-determining regions (QRDR) including gyrA, gyrB, parC and parE genes in Streptococcus pneumoniae. Br J Biomed Sci. 2012; 69(3): 123-5. PMid: 23057160.

[12] Ubukata K, Iwata S, Sunakawa K. In vitro activities of new ketolide, telithromycin, and eight other macrolide antibiotics against Streptococcus pneumoniae having mefA and ermB genes that mediate macrolide resistance. J Infect Chemother. 2003 Sep; 9(3): 221-6. PMid: 14513389. http://dx.doi.org/10.1007/s10156-003-0258-2

[13] Woodford, N., Sundsfjord, A. Molecular detection of antibiotic resistance: when and where? J. Antimicrob. Chemother. 2005 Aug; 56 (2): 259-261. PMid: 15967769. http://dx.doi.org/10.1093/jac/dki195

[14] Tang YW. Molecular diagnostics of atypical pneumonia. Acta Pharmacol Sin. 2003 Dec; 24(12): 1308-13. PMid: 14653964.

[15] Ost DE, Poch D, Fadel A, Wettimuny S, Ginocchio C, Wang XP. Mini-bronchoalveolar lavage quantitative polymerase chain reaction for diagnosis of methicillin-resistant Staphylococcus aureus pneumonia. Crit Care Med. 2010 Jul; 38(7): 1536-41. PMid: 20473148. http://dx.doi.org/10.1097/CCM.0b013e3181e2ca78

[16] Schulte B, Eickmeyer H, Heininger A, Juretzek S, Karrasch M, Denis O, et al. Detection of pneumonia associated pathogens using a prototype multiplexed pneumonia test in hospitalized patients with severe pneumonia. PLoS One. 2014 Nov; 9(11): e110566, eCollection 2014. http://dx.doi.org/10.1371/journal.pone.0110566

[17] Höffken G, Lorenz J, Kern W, Welte T, Bauer T, Dalhoff K, et al. Guidelines of the Paul-Ehrlich-Society of Chemotherapy, the German Respiratory Diseases Society, the German Infectious Diseases Society and of the Competence Network CAPNETZ for the Management of Lower Respiratory Tract Infections and Community-acquired Pneumonia. Pneumologie. 2010 Mar; 64(3): 149-54. http://dx.doi.org/10.1055/s-0029-1243910. [Epub 2010 Feb 23] 